DOI: https://doi.org/10.47405/mjssh.v5i5.395

\begin{tabular}{|c|c|}
\hline 1. 1.54 & Malaysian Journal of Social Sciences and Humanities (MJSSH) \\
\hline $\begin{array}{c}\text { Malaysian Journal of } \\
\text { solal sciences and }\end{array}$ & Volume 5, Issue 5, May 2020 \\
\hline (MJ-SSH) & e-ISSN : 2504-8562 \\
\hline & $\begin{array}{l}\text { Journal home page: } \\
\text { www.msocialsciences.com }\end{array}$ \\
\hline
\end{tabular}

\title{
Dokumentasi Tanah Wakaf di Negeri Terengganu Sebelum Kemerdekaan dan Implikasinya Terhadap Keputusan Jawatankuasa Fatwa
}

\author{
Mohd Ridzuan Bin Mohamad', Zurita Binti Mohd Yusoff', Nadhirah Binti Nordin'1 \\ ${ }^{1}$ Fakulti Islam Kontemporari (FKI), Universiti Sultan Zainal Abidin (UniSZA)
}

Correspondence: Mohd Ridzuan Bin Mohamad (duan_shi@yahoo.com)

\begin{abstract}
Abstrak
Dokumentasi wakaf merupakan sebuah dokumen bertulis yang sah menurut perundangan wakaf dan hukum syarak. Ia telah wujud sebelum kemerdekaaan lagi. Ia mengandungi empat rukun wakaf iaitu wāqif, mauquf, mauquf alaihi dan sighah. Walau bagaimana pun, dokumentasi wakaf yang dilakukan sebelum kemerdekaan ini mengandung ayat yang masih mengelirukan jika diadaptasi dengan undangundang yang berkuatkuasa pada masa kini iaitu status tanah wakaf dibatalkan dan ditukar kepada tanah bukan wakaf oleh Pihak Berkuasa Negeri. Kekeliruan tersebut adalah pembatalan penyataan wakaf pada tahun 1982. Oleh itu, kajian ini dilakukan untuk meneliti semula salah satu sampel dokumentasi pendaftaran wakaf iaitu KSB 460 Mukim Kuala Terengganu. Kajian ini menggunakan pendekatan kualitatif serta memperoleh data kajian melalui analisis dokumen dan temu bual. Kajian ini mendapati Pada tahun 1982, dokumentasi wakaf ini telah ditukarkan kepada tanah rezab kerajaan di bawah perundangan Kanun Tanah Negara 1965 Seksyen 62 dan implikasinya status wakaf tersebut terbatal. Percanggahan status tanah tersebut berdasarkan catatan dalam dokumen pada tahun 1950 telah dirujuk semula di peringkat Jawatankuasa Fatwa Negeri Terengganu pada tahun 2015 dan keputusannya bahawa tanah tersebut merupakan tanah wakaf walaupun berstatus tanah rezab kerajaan. Rumusan kajian ini menunjukan bahawa sebuah dokumentasi wakaf adalah penting bagi menjamin sesebuah harta wakaf atau mauquf supaya berada pada tahap yang sentiasa terjamin keabsahannya di samping juga ia merupakan suatu ketetapan hukum syarak. Oleh demikian, dokumentasi tanah wakaf merupakan juga suatu hubungan terhadap pelaksanaan hukum syarak secara lengkap.
\end{abstract}

Kata kunci: wakaf, dokumentasi, jawatankuasa Fatwa, sebelum kemerdekaan

\section{Pre-Independence Wakaf Documents in Terengganu and Its Implication on Decisions by the Fatwa Committee}

\begin{abstract}
Wakaf documents are a legal written document according to wakaf law and the syarak, which has existed before this country's independence. It contains the four pillars of wakaf, namely wāqif, mauquf, mauquf alaihi and sighah. However, pre-independence wakaf documents contain clauses that are confusing when adapted into contemporary legislation, such as the status of wakaf land that has been annexed or converted into non-wakaf land by the State authority. The confusion occurred after the wakaf status annexation was declared in 1982. Hence, this study re-examined a sample of the wakaf registration document, namely KSB 460 Mukim Kuala Terengganu. This study is qualitative in nature and obtained data through document analysis and interviews. Findings show that in 1982 the wakaf document was converted to government reserve land according to provisions under the National Land
\end{abstract}


Code 1965 Section 62 and the implication was that the wakaf status was annulled. The contradiction concerning the status of the land based on what was written on the document in 1950 was referred to the Terengganu State Fatwa Committee in 2015. The decision was that it is still wakaf land although its status is government reserve land. It can be concluded that a wakaf document is important to ensure that the legitamacy of the wakaf property or mauquf is always safeguarded besides adhering to stipulations mentioned in the syarak. Therefore, wakaf land documents, to a large extend, compliment the implementation of syarak.

Keywords: wakaf, documentation, Fatwa committee, pre-independence

\section{Pengenalan}

Dokumentasi dari sudut istilah adalah bahan bercetak yang dimuatkan segala falsafah tindakan seperti elemen 'persetujuan', 'geran', 'surat', 'resit' dan ia digunakan sebagai bahan bukti kepada suatu fakta (Saadon Awang, 2012). Dokumentasi dan pelaksanaan wakaf mempunyai hubungan penting kerana salah satu daripada hukum wakaf adalah 'sighah'. Enakmen Wakaf (Terengganu) 2016 telah menyebut tentang kedudukan 'sighah' di bawah seksyen 2 (1) (a):

'Pernyataan wakaf sama ada secara lisan, bertulis atau isyarat'.

Elemen-elemen yang merangkumi sebuah dokumentasi wakaf ialah teknik pendaftaran, pemahaman terhadap komponen kandungan dan proses penyimpangan (Mustapahayudin, 2018). Dokumentasi tanah wakaf merupakan sebuah bahan bukti bertulis yang penting jika wujud pertikaian pada masa akan datang. Justeru itu, mana-mana isi kandungannya yang bercanggah dengan pelaksanaan, maka proses penilaian semula dilaksanakan. Pelaksanaan ini akan disemak oleh pihak MAIDAM dan seterusnya akan di bawa ke Jawatankuasa Fatwa Negeri Terengganu untuk mendapatkan status keputusan dokumen tersebut sama ada sah atau tidak (Roseli \& Fatimah, 2019). Jawatankuasa fatwa mempunyai bidang kuasa dalam menentukan sesuatu perkara berkaitan kedudukan wakaf termasuk kekeliruan terhadap sesebuah suratcara atau dokumentasi sebagai mana termaktub di dalam Enakmen Wakaf (Terengganu) 2016 seksyen 41 (1):

'Jika terdapat apa-apa persoalan Hukum Syarak berkait dengan rukun wakaf, atau perkara yang bersampingan dengannya yang perlu diputuskan, Majlis hendaklah merujuk kepada Jawatankuasa Fatwa tentang persoalan itu’.

Dasar ini turut dimuatkan juga Enakmen Pentadbiran Hal Ehwal Islam (Terengganu) 2001 seksyen 68:
'Jika, pada pendapat Majlis makna atau natijah mana-mana suratcara atau akaun yang mewujudkan atau menyentuh mana-mana wakaf atau nazar adalah kabur atau tidak pasti, Majlis bolehlah merujukkan perkara itu kepada Jawatankuasa Fatwa bagi mendapatkan pendapatnya tentang makna dan natijah suratcara atau akaun itu, dan hendaklah bertindak menurut apa-apa pendapat yang diberikan sedemikian oleh Jawatankuasa Fatwa itu'

Namun, sesebuah dokumentasi wakaf yang dijumpai sebelum kemerdekaan di negeri Terengganu sukar untuk dipastikan kedudukan wakaf sama ada sah atau tidak kerana kandungan adalah mengelirukan. Susulan itu, dokumentasi tersebut perlu diputuskan secara muktamad oleh pihak jawatankuasa fatwa sama ada sah atau tidak bagi kedudukan wakaf yang berkaitan (Roseli \& Fatimah, 2019).

Kajian yang dijalankan ini berbentuk kualitatif dan menggunakan kaedah analisis dokumen. Analisis ini digunakan secara diskriptif, serta turut digunakan juga kaedah pemerhatian deduktif dan induktif. Dokumen asal merupakan rujukan primer disamping data-data diperlohi melalui proses temu bual. para responden adalah terdiri daripada pakar dalam bidang berkenaan. Responden pertama ialah Mohd Jalil Bin Ngah selaku Ketua Penolong Kanan Setiausaha Pembangunan dan Projek. Beliau telah bertugas di 
DOI: https://doi.org/10.47405/mjssh.v5i5.395

MAIDAM lebih daripada 20 tahun. Responden kedua ialah Roseli Bin Yusof yang merupakan Penolong Pegawai Tanah dan berpengalaman lebih daripada 25 tahun dalam bidang ini. Responden ketiga pula ialah Fatimah Binti Harun yang menjawat jawatan Penolong Pegawai Wakaf selama lebih daripada 10 tahun.

\section{Dokumentasi Wakaf Terengganu}

Pihak yang bertanggungjawab terhadap pengurusan wakaf adalah Majlis Agama Islam Negeri (MAIN). Hal tersebut selaras dengan perundangan di negara ini sebagaimana termaktub dalam Perlembagaan Pesekutuan di bawah 'Jadual Kesembilan' iaitu 'Senarai Negeri'. Bagi negeri Terengganu, pengurusan wakaf adalah di bawah jagaan sepenuhnya oleh pihak Majlis Agama Islam Dan Adat Melayu Terengganu (MAIDAM selaras pengurusan wakaf di Terengganu juga selaras dengan Enakmen Wakaf (Terengganu) 2016 Seksyen 4 (1) yang menyatakan:

'Majlis hendaklah menjadi pemegang amanah tunggal bagi semua wakaf, yang terletak hak di dalam Negeri Terengganu'.

Beberapa undang-undang sebelum ini juga telah menyatakan kedudukan berkenaan iaitu Enakmen Pentadbiran Hal Ehwal Islam (Terengganu) 2001 Seksyen 63, Enakmen Pentadbiran Hal Ehwal Islam (Terengganu) 1986 Seksyen 143 dan Administration Of Muslim Law Enactment (Terengganu) 1955 Section 59.

Dokumentasi wakaf di Terengganu telah lama dilaksanakan oleh pihak MAIDAM. Dokumentasi wakaf mempunyai hubungan rapat dengan kaedah-kaedah pendaftaran tanah di bawah perundangan Kanun Tanah Negara 1965 iaitu proses pindah milik tanah 'Borang 14, ${ }^{\text {A }}$ di bawah Seksyen 215. Kini, dokumentasi yang digunapakai disebut sebagai 'Borang Ikrar Wakaf. Borang ini boleh didapati secara online dalam website rasmi MAIDAM dan memudahkan sesiapa yang hendak mewakafkan tanah. Borang Ikrar Wakaf boleh dimuat turun melalui website tersebut dan perlu hantar secara 'hardcopy' ke jabatan berkenaan untuk proses pendaftaran (Roseli, Fatimah 2019). Pengisian borang ini adalah tertakluk kepada beberapa terma dan syarat:

i. Boleh menulis dalam bahasa jawi dan Melayu

ii. Mestilah diakui atau ditandatangani oleh dua orang saksi

iii. Mertakan salinan kad pengenalan dan geran hak milik tanah

Kandungan yang ada dalam borang ini melibatkan beberapa komponen yang telah ditetapkan sebagaimana merujuk Enakmen Wakaf (Terengganu) 2016 iaitu perihal pewakaf atau 'wāqif' di bawah Seksyen 13 (1), perihal harta wakaf atau 'mauquf' di bawah Seksyen 23 (1), (2), (3) dan perihal tujuan wakaf atau mauquf alaihi' di bawah Seksyen 22.

\section{Wakaf Sebelum Kemerdekaan}

Tanah-tanah yang wujud sebelum kemerdekaan adalah berdasarkan kepada undang-undang tubuh negeri masih-masing dan termasuk juga undang-undang adat yang berkuatkuasa ketika itu (Nazri Abdullah, 1985). Bagi negeri Terengganu, undang-undang tanah yang dikuatkuasakan pada sebelum kemerdekaan antaranya ialah 'Enakmen Rezab Melayu Terengganu 1941 (Salleh Buang, 1993). Terdapat beberapa rekod dokumentasi tanah wakaf di MAIDAM sekitar tahun 1950 an. Jenis dokumentasi ini di sebut sebagai 'Kenyataan Settlement Bilangan' atau singkatan KSB. KSB merupakan salah satu geran tanah yang diguna pakai pada masa dahulu. Tarikh hak milik tersebut dicatatkan sebelum kemerdekaan lagi dan urusan pendaftaran tanah dikendalikan oleh pihak Pejabat Tanah Daerah. Dari sudut undang-undang tanah, KSB adalah berdasarkan kepada 'Settlement Enactment 65-1356 dan seterusnya ditukarkan kepada 'Keterangan Register Mukim (KRM)' di bawah 'Land Enactment 3/1357'. Kini geran KSB dan KRM tidak lagi diguna pakai dan geran tanah terkini mempunyai beberapa peringkat yang dikuatkuasakan di bawah 'Kanun Tanah Negara 1956' iaitu Geran Mukim 'GM', Geran Negeri 'GN', Pajakan Mukim 'PM', Pajakan Negeri 'PN', Hakmilik 
DOI: https://doi.org/10.47405/mjssh.v5i5.395

Sementara Mukim 'HS(M) dan Hakmilik Sementara Daftar 'HS(D). (PTG, 2005). Geran tanah wakaf pada masa kini mempunyai kesemua jenis-jenis hak milik tersebut seperti GM, GN, PN, PM, HS(M) dan HS(D). Mengenai tanah wakaf yang berstatus 'PN' atau 'PM', ia mempunyai suatu tempoh masa terhadap pegangan hak milik dan berakhir selepas tamat tempoh tersebut. Setelah tamat, tanah tersebut dikembalikan semula kepada Pihak Berkuasa Negeri dan dijadikan sebagai tanah rezab. Oleh kerana tanah wakaf adalah bersifat kekal, maka bagi sesiapa yang hendak mewakafkan tanah yang berstatus pajakan sama ada PN atau PM ia dibenarkan. Ini berdasarkan keputusan Jawatankuasa Fatwa Kebangsaan Kali Ke 65 yang bersidang pada 13 Oktober 2014:

'Hukum wakaf bagi tanah hak milik terhad (leasehold) atau pajakan adalah sah dan diterima oleh syarak'

Setiap pegangan hak milik tanah wakaf adalah penting dilihat dari sudut hukum syarak. Ini kerana sebuah pegangan hak milik merupakan pembuktian terhadap tanah-tanah wakaf yang sah dari sudut perundangan dan ia tidak boleh disangkal, diceroboh ke atas tanah tersebut. Namun demikian, bagai mana pula status hak milik tanah wakaf yang telah lama didaftarkan iaitu KSB, adakah ia dilindungi di bawah perundangan dan apakah pula implikasi hukum syarak terhadap status hak milik tersebut. Justeru, perbincangan mengenainya banyak sudut dilihat. Kini rekod tanah wakaf secara keseluruhannya mempunyai hak milik terbaru dan sedikit sahaja yang berstatus KSB. Maklumat yang diberikan oleh pihak MAIDAM bagi tanah wakaf yang berstatus tapak kubur iaitu keterangan tanah KSB sebagai mana berikut:

Jadual 1: Rekod Tanah Wakaf Berstatus KSB

\begin{tabular}{lll}
\hline No KSB & Mukim & Daerah \\
\hline 460 & Bandar & Kuala Terengganu \\
4008 & Bandar & Kuala Terengganu \\
2034 & Bandar & Kuala Terengganu \\
2400 & Bandar & Kuala Terengganu \\
2425 & Bandar & Kuala Terengganu \\
2611 & Bandar & Kuala Terengganu \\
2001 & Bandar & Kuala Terengganu \\
2776 & Bandar & Kuala Terengganu \\
905 & Bandar & Kuala Terengganu \\
3877 & Bandar & Kuala Terengganu \\
509 & Bandar & Kuala Terengganu \\
2064 & Bandar & Kuala Terengganu \\
\hline
\end{tabular}

(MAIDAM: 2019)

Salah satu sampel dokumen wakaf yang ditemui oleh pihak MAIDAM pada sebelum kemerdekaan iaitu sebidang tanah wakaf terletak di kampung Tanjung Kuala Terengganu yang berketerangan KSB 460. Menurut pihak MAIDAM, status tanah tersebut sukar untuk dibuat pengesahan sebagai tanah wakaf kerana terdapat beberapa isu dan rujukan dokumen asal sebagai mana rajah di bawah: 
DOI: https://doi.org/10.47405/mjssh.v5i5.395

\section{Rajah 1: Dokumen Asal Tanah Wakaf Sebelum Kemerdekaan}

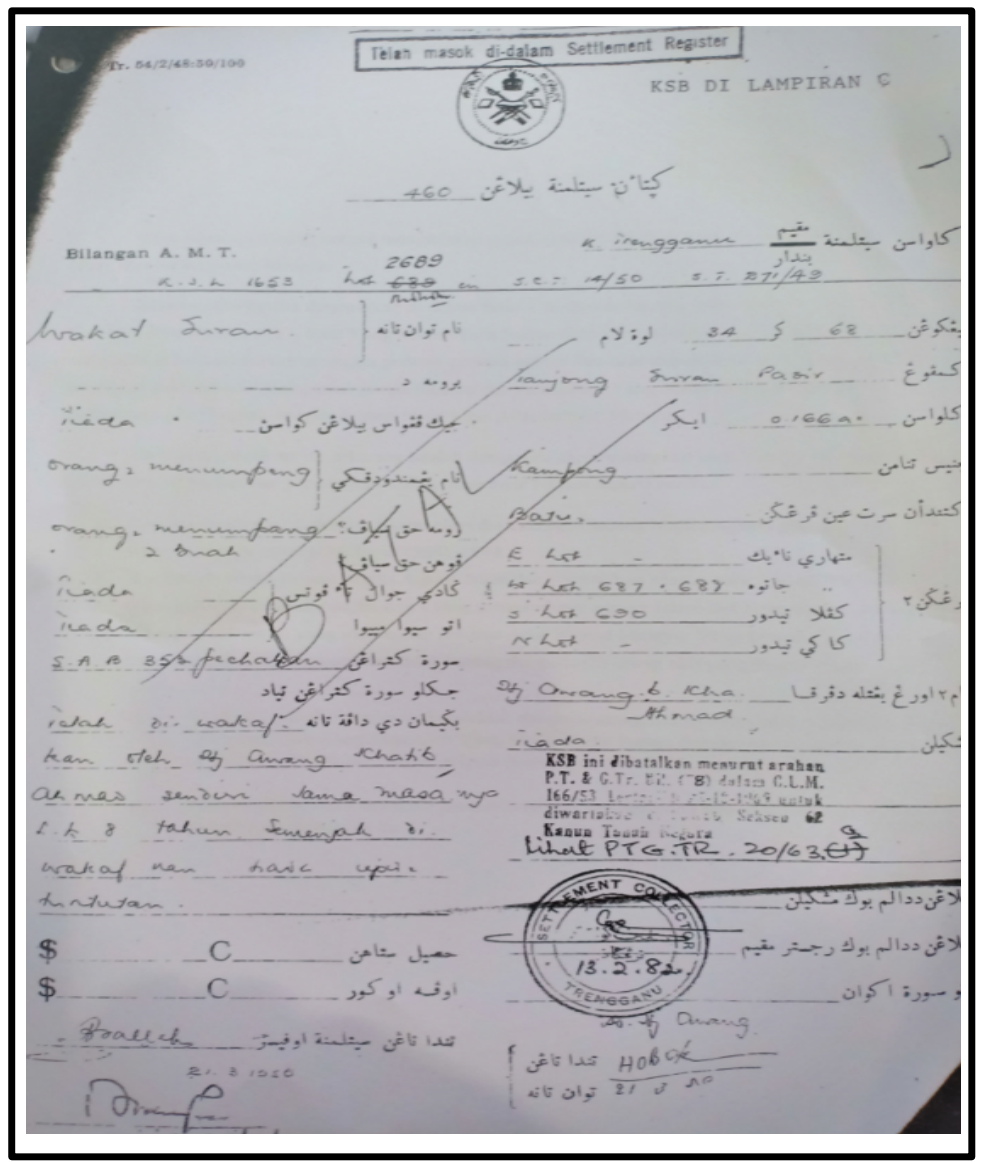

\section{Dapatan Kajian}

Berdasarkan rajah 1 di atas, penelitian secara diskriptif mendapati bahawa struktur komponen ini terdapat 3 kedudukan iaitu arah atas, kanan dan kiri. Arah atas mengandungi 2 baris keterangan, arah kanan mempunyai 11 baris keterangan dan arah kiri pula mengandungi 15 baris keterangan. Keterangan secara terperinci adalah sebagaimana Jadual 2 di bawah:

Jadual 2: Analisis KSB 460 Mukim Kuala Terengganu

\begin{tabular}{lll}
\hline Susunan & \multicolumn{1}{c}{ Komponen } & Keterangan Butiran \\
\hline Atas Pertama & Logo Negeri Terengganu & Bujur \\
Atas Kedua & Kenyataan Senttiment Bilangan & 460 \\
Kanan Baris 1 & Mukim & Kuala Terengganu \\
Kanan Baris 2 & Lingkungan & 68 \\
Kanan Baris 3 & Kampung & Tanjung Surau Pasir \\
Kanan Baris 4 & Keluasan & $0.166 \mathrm{a}$ ' / ekar \\
Kanan Baris 5 & Jenis tanaman & kampung \\
Kanan Baris 6 & Ketandaan serta perengang & Batu \\
& Matahari naik & E hst \\
& Matahari jatuh & $\mathrm{W}$ hst 687. 688 \\
& Kepala tidur & $\mathrm{S} \mathrm{hst} \mathrm{690}$ \\
& Kaki tidur & $\mathrm{N}$ hst - \\
Kanan Baris 7 & Nama orang yang telah diperiksa & $\mathrm{Hj}$ Awang b Ahmad \\
Kanan Baris 8 & Musykilan & Tiada \\
\hline
\end{tabular}


DOI: https://doi.org/10.47405/mjssh.v5i5.395

\begin{tabular}{lll}
\hline Kanan Baris 9 & Bilangan di dalam buku musykilan & - \\
Kanan Baris 10 & $\begin{array}{l}\text { Bilangan di dalam buku rigester } \\
\text { mukim }\end{array}$ & - \\
Kanan Baris 11 & Atau Surat Akuan & Haji Awang \\
Kiri Baris 1 & Bilangan A.M.T & \\
Kiri Baris 2 & Bilangan K.S.L & 1653 lot 2689 \\
Kiri Baris 3 & Nama tuan tanah & Wakaf Surau \\
Kiri Baris 4 & Berumah di & - \\
Kiri Baris 5 & Jika penguasa bilangan kawasan & Tiada \\
Kiri Baris 6 & Nama yang menduduki & Orang2 menumpang \\
Kiri Baris 7 & Rumah hak siapa & Orang2 menumpang \\
Kiri Baris 8 & Pohon hak siapa & Tiada \\
Kiri Baris 9 & Atau sewa menyewa & Tiada \\
Kiri Baris 10 & Surat keterangan & S.A.B 353 \\
Kiri Baris 11 & Bagaimana dia dapat tanah & Ialah di wakafkan oleh \\
& & Haji Awang Khatib \\
& & sendiri lama masanya \\
& & L.K 8 tahun, semenjak \\
& & diwakaf tiada apa-apa \\
& & tuntutan. \\
Kiri Baris 12 & Hasil setahun & - \\
Kiri Baris 13 & Upah ukur & - \\
Kiri Baris 14 & Tandatangan Opisbur & 21.3 .1950 \\
Kiri Baris 15 & Tandatangan Tuan Tanah & 21.3.1950 \\
\hline
\end{tabular}

Merujuk Jadual 2 di atas, komponen yang dimuatkan dalam dokumen tersebut mendapati 4 parameter wakaf iaitu wāqif, mauquf, mauquf alahi dan sighah. Namun demikian, selepas meneliti seluruh kandungan dokumentasi ini, permasalahan yang didapati pada susunan kandungan 'Kanan Baris 8' iaitu di bawahnya terdapat cop pengesahan atau endorsement oleh Pihak Berkuasa Negeri (PBN) menyatakan:

KSB ini dibatalkan menurut arahan P.T. \& G.Tr bil (8) dalam C.L.M 166/53 bertarikh 25.12.1969 untuk diwartakan di bawah Seksyen 62 Kanun Tanah Negara. Lihat PTG.TR.20/63.(2).

Tarikh: 13.2.1982.

Berdasarkan kepada perundangan Kanun Tanah Negara 1965 di bawah Seksyen 62, tanah-tanah yang diwartakan di bawah peruntukan ini merupakan tanah rezab kerajaan. Implikasi perundangan tersebut telah membatalkan hak milik asal iaitu status tanah hak milik bertukar sebagai tanah rezab kerajaan (JTGP, 1980). Contoh yang berlaku ke atas tanah wakaf berstatus KSB yang dibatalkan iaitu pada tahun 2015, tanah ini terlibat dengan projek pembangunan di kampung Tanjung, Bandar Kuala Terengganu dan surau tersebut telah dirobohkan. Proses merobohkan surau tersebut mengambil kira bahawa tanah tersebut merupakan hak milik kerajaan di bawah Seksyen 62 Kanun Tanah Negara dan bukannya sebagai tanah wakaf. Perkara ini menjadi perhatian oleh beberapa jabatan yang terlibat iaitu Pejabat Tanah Dan Galian Negeri Terengganu (PTG), MAIDAM dan Lembaga Tabung Amanah Warisan Negeri Terengganu (LTAWNT). MAIDAM telah mengesyorkan supaya permasalahan ini perlu dirujuk kepada Jawatankuasa Fatwa Negeri Terengganu kerana status tanah tersebut sama ada menjadi tanah wakaf atau tidak bukan lagi di bawah bidang kuasa jabatan ini. Dalam hal ini juga, memberi kesan tehadap perobohan surau di atas tanah berkenaan (Jalil Ngah, 2019). Susulan itu, pihak pengurusan MAIDAM telah membawa permasalahan ini ke Jabatan Mufti dan keputusan dibuat oleh Jawatankuasa Fatwa Negeri Terengganu Kali Ke-10 Penggal Ke-11 bertarikh 18 Syawal 1436 bersamaan 3 Ogos 2015 :

'...Bagi mengekalkan hasrat asal pewakaf, maka tapak surau yang diambil hendaklah digantikan dengan tapak yang bersebelahan dengan keluasan yang sama. Bahagian bangunan surau yang dirobohkan pula hendaklah dibina semula ditapak gantian tersebut.' 
Merujuk keputusan jawatankuasa fatwa ini bahawa tanah tersebut disahkan sebagai tanah wakaf kerana terdapat syarat-syarat wakaf perlu dikuatkuasakan walaupun mengikut perundangan tanah bahawa tanah ini bukan lagi sebagai tanah wakaf. Syarat yang ditetapkan dalam keputusan fatwa ini iaitu mestilah melaksanakan proses istibdāl. Istibdāl merupakan gantian harta wakaf yang telah hilang mauqufnya (Abu Zahrah, 1971). Terdapat juga keputusan fatwa Negeri Terengganu yang lain bagi menjelaskan mengenai kedudukan Istibdāl tanah wakaf yang diambil oleh Pihak Berkuasa Negeri (PBN) iaitu bertarikh 26 Jamadil Awal 1411 bersamaan 31 Disember 1990:

'Tanah wakaf yang dimabil balik hendaklah digantikan dengan tanah yang sepertinya dan kemudian dilafazkan dengan sighah wakaf'

Berdasarkan perbincangan kajian di atas, dokumentasi tanah wakaf di negeri Terengganu pada masa sebelum kemerdekaan telah dimuatkan di dalam 'Kenyataan Settlement Bilangan' (KSB). Di dalamnya terkandung rukun wakaf iaitu wäqif, mauquf dan mauquf alaihi. Secara perbandingan, komponan KSB dengan parameter wakaf mempunyai hubungan yang sama. Secara deskriptif mendapati bahawa persamaannya sebagai mana keterangan di bawah:

Jadual 3: Hubungan KSB dengan Parameter Wakaf

\begin{tabular}{lll}
\hline Parameter Wakaf & Keterangan KSB & Butiran \\
\hline Wäqif & Kiri Baris 11 & Haji Awang Khatib \\
Mauquf & Atas Kedua, Kanan & Sebidang Tanah berketerangan \\
& Baris 1, 2, 3, 4. & KSB 460 Mukim Kuala \\
& & Terengganu, Kampung Tanjung \\
& & seluas 0.166 hektar. \\
Mauquf Alahi & Kiri Baris 3 & Wakaf surau \\
\hline
\end{tabular}

Implikasi keputusan fatwa terhadap pembatalan tanah wakaf ini pada 13 Februari 1982 tidak memihak kepada undang-undang sivil yang membatalkan status tanah wakaf dan diwarta sebagai tanah rezab kerajaan di bawah Kanun Tanah Negara Seksyen 62. Jika dibandingkan pula keputusan fatwa ini dengan undang-undang wakaf pada tahun 2016 (Enakmen Wakaf Terengganu), tanah tersebut dikira sah sebagai tanah wakaf. Hal ini merujuk kepada peruntukan undang-undang yang terdapat di bawah Seksyen 21:

'Sesuatu wakaf yang disempurnakan menurut Hukum Syarak tidak boleh dibatalkan..'

Seksyen 41 (2) menyatakan pula menyatakan:

'Segala keputusan Jawatankuasa Fatwa hendaklah menjadi muktamad'

Secara induktif, dapat disimpulkan bahawa pendaftaran wakaf pada masa tersebut mula dilaksanakan di pejabat tanah daerah. Pembukitan ini sebagai mana merujuk pada KSB 460 iaitu pada 'Kanan Baris 7' dengan menjelaskan bahawa Haji Awang b Ahmad merupakan kakitangan Pejabat Tanah Daerah Kuala Terengganu yang telah menyemak keterangan tanah tersebut untuk disahkan sebagai tanah wakaf. Manakala undang-undang wakaf dikuatkuasakan selepas KSB tersebut iaitu pada tahun 1955 di bawah 'Administration Of Muslim Law Enactment (Terengganu) 1955'Section 59:

'.the Corporation shall be the sole Controller of all wakaf, whether wakaf 'am or
wakaf khas..'

\section{Kesimpulan}

Dokumentasi wakaf adalah termasuk sighah wakaf yang dibentuk secara bertulis. Sighah wakaf juga termasuk salah satu rukun yang wajib dipenuhi. Hukum syarak menetapkan bahawa antara syarat bagi 
DOI: https://doi.org/10.47405/mjssh.v5i5.395

harta wakaf mestilah bersifat kekal bagi menjamin sesebuah harta wakaf. Sebuah dokumentasi yang jelas dan terperinci pastinya memudahkan rujukan sekiranya berlaku apa sahaja perkara yang berbangkit. Dokumentasi wakaf juga berperanan penting sehingga menjangkaui pada masa akan datang untuk mengesahkan dan membuktikan status sesebuah harta wakaf. Buktinya, KSB sebagai sebuah dokumen wakaf pada masa dahulu tetap dijamin keabsahanya kedudukan wakaf tersebut sehingga sekarang. Penulisan artikel ini juga telah membuktikan bahawa dokumen KSB telah memainkan peranan penting dalam menyelesaikan masalah pengurusan tanah wakaf. Walaupun pada masa tersebut Tanah Melayu berada di bawah penjajahan British, namun beberapa aspek pengurusan wakaf telah dilaksanakan dengan baik seperti pendaftaran wakaf dalam KSB.

\section{Rujukan}

Abu Zahrah (1971) 'Muhaḍarāt fi al-Waqf' Kaherah: Dār al-Fikr, ed, 2.

Dokumen 'Kenyataan Settlement Bilangan KSB' 460 Mukim Kuala Terengganu.

Enakmen Wakaf (Terengganu) 2016 (Enakmen 1/2016).

Enakmen Pentadbiran Hal Ehwal Islam (Terengganu) 2001 (Enakmen 2/2001).

Jabatan Tanah Dan Galian Persekutuan (1980), Buku Panduan Pentadbiran Tanah, Kuala Lumpur: Percetakan Negara, ed 1.

Jalil Ngah, Roseli Yusof Dan Fatimah Harun 'Kajian Dokumentasi Tanah Wakaf Di Negeri Terengganu (Sebelum Kemerdekaan) Dan Implikasinya Tehadap Keputusan Jawatankuasa Fatwa'. Temubual 11 November 2019.

Mustapahayuddin (2018). May Waqf 0.2. Kertas Kerja Seminar 'Bagaimana Mendokumenkan Suratcara Wakaf (Hujjah Wakaf)'. Anjuran Pusat Pengajian Islam Universiti Malaya (UM), Kuala Lumpur. 10 Disember.

Nazri Abdullah (1985), Melayu Dan Tanah, Petaling Jaya: Media Intelek Sdn Bhd, ed 1.

Portal Rasmi Majlis Agama Islam Dan Adat Melayu Terengganu (MAIDAM): http://www.maidam.gov.my/index.php/en/cara-memohon-bantuan-zakat-maidam

Portal Rasmi Pejabat Tanah Dan Galian Negeri Terengganu (PTG) : http://ptgweb.terengganu.gov.my/ Pejabat Tanah Dan Galian Negeri Terengganu (PTG). 2005. Kertas kerja seminar 'Penyelesaian Pusaka Kecil bagi Penghulu Dan Pengawal' Anjuran PTG, Terengganu. 31 Mac.

Salleh Buang (1993), Undang-Undang Tanah Di Malaysia, Kuala Lumpur: Dewan Bahasa Dan Pustaka, ed 1.

Surat Jabatan Mufti Negeri Terengganu JMN. Tr 1/4 Bhg 2 bil ( 53) bertarikh 13 Disember 1990.

Surat Jabatan Mufti Negeri Terengganu JMN. TR. 610 /1/6/4 JLD 4. (69) bertarikh 18 Disember 2015. 